\title{
Produções do invisível: considerações sobre o tempo e a formação de professores
}

\author{
Alice Copetti Dalmaso* \\ Deisi Sangoi**
}

\section{Resumo}

O presente texto se propõe a abordar, mesmo que brevemente, a temática da invenção no âmbito da formação de professores. Para tanto, faremos um apanhado das contribuições de Virgínia Kastrup a esse respeito, trazendo a questão do tempo - através da problematização de duração, de Henri Bergson - e seu emprego na temática da formação. A partir disso, tentaremos desconstruir um olhar de referência identitária na contemporaneidade para modos de existência que se percebem múltiplos e abertos. Na processualidade que se trata em explicar, nos movimentos inventivos que funcionam com ela, o tempo é considerado como expressão da dimensionalidade do ser individuando-se. Ou seja, durar refere-se a uma imediatidade do ser, do tempo de ser, que é modulável, mutante, sempre em devir, sempre em criação. Na construção de produzir um corpo que abandona uma referência identitária - que diverge com a transformação de si - inevitavelmente reportamo-nos à relação da ideia de tempo como duração com a operação de individuação de Gilbert Simondon. É do intercruzamento destes conceitos, e sua possível ressonância no debate que concerne a políticas formativas, que se pode desenvolver um olhar do invisível a uma formação de professores, de aprendizes de outros modos de operar no mundo. A invenção como alavanca nos direciona a um campo de possibilidades de conceber e vivenciar um outro tempo (e espaço) que é ele mesmo produção de subjetividades, singularidades e diferenças.

Palavras-chave: tempo, individuação, formação de professores.

\section{Productions of invisible: considerations about time and training of teachers}

\section{Abstract}

This paper aims to approach, even though in a briefly way, the subject of invention in the training of teachers. In order to do this, we will make a brief overview on Virgínia Kastrup contributions about this issue. One of the questions is the time - through Henri Bergson's duration concept and its using in training theme. From this point, we will try to deconstruct a view about the identity reference in

\footnotetext{
* Mestranda do Programa de Pós-Graduação em Educação na Universidade Federal de Santa Maria (UFSM).

** Professora Doutora da Universidade Federal de Santa Maria, Centro de Educação, Departamento de Metodologia do Ensino.
} 


\section{Alice Copetti Dalmaso - Deisi Sangoi}

contemporaneity toward to multiple and open ways of existence. In the inventive movements of the processuality, the time is considered as an expression of human being individuation. It means to last refer to an immediacy of being, of being time, which are modulable and mutant, always in a creation process. In a movement of building a body which leaves an identity reference - that is opposite of self-transformation - necessarily we report us to the relation between the idea of time as duration and the individuation principle by Gilberto Simondon. With these concepts and their possible resonance in the discussion about formative politics, we can develop a view over the invisible to training of teachers and over the learners and another ways of operating in the world. The invention as a lever direct us to a field of possibilities to conceive and experience another time (and space) which is producer of subjectivity, singularities and differences.

Keywords: time; individuation; teachers training.

O presente texto se propõe a abordar, de forma breve, a temática da invenção no âmbito da formação de professores. Para tanto, faremos um apanhado sobre as contribuições de Virgínia Kastrup a esse respeito, trazendo a questão do tempo - através da problematização de duração, de Henri Bergson - e sua relação com a identidade na formação. Ainda, mesmo que de forma inicial, será imprescindível relacionar a ideia de tempo com o príncípio de individuação e devir de Gilbert Simondon, intercruzando-se com a duração e sua possível ressonância no debate que concerne a políticas formativas. Esses são os principais conceitos trazidos aqui para nos ajudar a compor um novo tempo (e espaço) para a formação humana.

O ímpeto de escrever sobre o tempo e sobre os modos de existência na formação de professores surge de nosso encontro constante com os escritos da psicóloga Virgínia Kastrup e suas problematizações com relação à temática da invenção em seus estudos epistemológicos da cognição. Kastrup constata que a psicologia da invenção inexiste. Afirma que é na atualidade, e saindo do âmbito do discurso psicológico existente, que a invenção aparece em seu caráter problemático (sob diversas formulações, ela aparece em estudos de llya Prigogine, Isabel Stengers, Gilles Deleuze; Felix Guattati, Henri Bergson, Frederich Nietzsche, entre outros) e que é possível constatar a ausência de seu tratamento pela psicologia. Determinada por seu projeto epistemológico, o qual se encontra enraizado na modernidade, a psicologia atual entende a cognição como espaço de representação. Espaço que opera segundo leis científicas universais, restando ao problema uma "formulação feita em termos de forma, estrutura ou sistema cognitivo, que ocupa o espaço intermediário das relações entre o sujeito cognoscente e o objeto que se dá a conhecer" (KASTRUP, 2007, p. 21). Se a cognição invaria, explica Kastrup, a invenção torna-se um problema inexistente, pois o sistema cognitivo não está sujeito a surpresas, abalos, transformações. 
No entanto, para compreender melhor a determinação do projeto epistemológico da psicologia, Kastrup ateve-se à própria constituição da modernidade. Conforme a autora e sua análise sustentada em Foucault, a psicologia cognitiva (bem como toda ciência moderna) configurou seu projeto epistemológico e efetivou seu desenvolvimento apoiada em uma das vertentes da modernidade: a analítica da verdade. Vertente na qual se encontram as "filosofias pós-kantianas que trabalham sobre o tema do conhecimento, considerando a existência de limites que não podem ser ultrapassados" (2007, p. 22). 0 movimento da analítica da verdade opera em excluir completamente a dimensão temporal de seu objeto. É essa dimensão temporal - o resto da constituição da psicologia cognitiva explicitada - que Kastrup procura trazer para que a invenção surja. É na ontologia do presente - no qual as filosofias "tomam o tempo como algo que constitui a substância mesma do real que, nesse caso, é sempre passível de transformação, de redefinição e de ultrapassamento de seus limites" (p. 22) -, que a invenção poderá ser problematizada.

Lançando o que deve ser entendido sobre invenção, a autora utiliza-se da etimologia da palavra latina invenire, que significa "encontrar relíquias ou restos arqueológicos" (STENGERS apud KASTRUP 2007, p. 27), o que indica que a invenção não opera sob o signo da instantaneidade, implicando, sim, uma duração, "um trabalho com restos, uma preparação que ocorre no avesso do plano das formas visíveis" (p. 27). Kastrup traz Bergson para explicar a ontologia do presente e sua fundamentação pelo tempo, a duração.

Pensar a duração é fazer o movimento de pensar o próprio movimento das formas não visíveis. Duração são ações indivisíveis, vida interior que é variedade de qualidades, continuidade de momentos. As ciências em geral tendem a negar a duração, já que se atêm à forma visível dos seres vivos, de seus órgãos, estruturas, cabendo-lhe a tarefa de analisar. O que Bergson nos ajuda a visualizar é um querer conhecer relativamente, a disposição de nos "transpormos para o interior de um objeto para coincidir com o que ele tem de único, e consequentemente, inexprimível" (2005, p. 23).

As paradas virtuais no tempo: é o que a ciência considera ao se tratar de um objeto. O exemplo do objeto em movimento ajuda a visualizar a institucionalização de nossa ideia de tempo e duração:

A linha que medimos é imóvel, o tempo é imobilidade. A linha é o feito, o tempo é o que se faz e mesmo o que faz com tudo que se faça. Jamais a medida do tempo se relaciona à duração enquanto tal; contamos somente um certo número de extremidades de intervalos ou de momentos, quer dizer, em suma, de paradas virtuais no tempo. (BERGSON, 2005, p. 150)

Dessa perspectiva, no que a ciência é limitada? A ciência trata do tempo como se já tivesse passado, já que sua função é prever. O caráter de 


\title{
Alice Copetti Dalmaso - Deisi Sangoi
}

acontecimento, de intempestivo, de surpresa do tempo é desconsiderado. Extrai matematicamente do mundo aquilo que é previsível e suscetível de se repetir e ser calculado, o que não dura. Mas o que dura, "que a ciência elimina, que é difícil de conceber e de exprimir, nós a sentimos e vivemos" (BERGSON, 2005, p. 151). A estrutura do entendimento humano, o que Bergson chama de senso comum, igualmente às ciências, desvia o olhar da transição:

\begin{abstract}
Se insistimos, ele [entendimento humano] faz com que a mobilidade, apertada em intervalos cada vez menores à medida que aumenta o número de posições consideradas, recue, fuja, desapareça no infinitamente pequeno. Nada de mais natural, se a inteligência é destinada sobretudo a preparar e aclarar nossas ações sobre as coisas. Nossa ação apenas se exerce comodamente sobre pontos fixos, é, então, a fixidez que nossa inteligência busca; ela se pergunta onde o móvel está, onde o móvel estará, onde o móvel passa. (BERGSON, 2005, p. 152)
\end{abstract}

Para sair dessa representação intelectual do movimento, o filósofo nos provoca um esforço de vê-lo simples e uno. Esforço em termos a mobilidade em sua essência, deixando de pensá-la como a composição de posições do que se move. "Como, entretanto, não ver que a essência da duração está em fluir, e que com o estável acoplado, ao estável não se fará jamais algo que dure?" (p.154). Tempo que dura, mobilidade ao movimento, vida real que muda, fluxo, devir, continuidade de intensidades que mudam, a mudança ela mesma, e não estados justapostos. Mudança entendida como um acidente que se acrescentaria à estabilidade? Esse é o foco da inteligência.

Isso exclui a ideia de sucessão no tempo e da mudança. Sucessão está ligada a déficit, à supressão de alguma coisa. Tempo que sucede é aquele em que coexiste um espaço ideal onde alinhamos os acontecimentos passados, presentes e futuros. O que dura, ao contrário, é um tempo percebido como um bloco, globalmente, e não como momentos; duração que se revela como "criação contínua, ininterrupto jorro de novidade" (p.155). Tempo que se sucede abriga verdades que preexistem, em que qualquer acontecimento que ocorra projeta atrás de si sombras no passado, pré-existido, sob a forma de possível: "Daí vem o erro que vicia nossa concepção do passado; e daí vem, ainda, a nossa pretensão de antecipar, em todas as ocasiões, o futuro" (BERGSON, 2005, p. 159).

Neste ponto, Bergson nos provoca em aprendermos a deixar um pouco de lado a lógica da inteligência ${ }^{1}$ e traçarmos novos caminhos de pensamento e construção de conhecimento pela intuição. Intuição que é a verdadeira duração, já que a inteligência nega o tempo, intelectualizando-o e transformando-o em espaço, em que a duração é apenas um fantasma. Essa intuição apreende uma "sucessão que não é justaposição, um crescimento por dentro, o prolonga- 
mento ininterrupto do passado num presente que penetra no futuro" (p. 168). É uma consciência imediata, e alargada, porque se choca com o inconsciente. É realidade e concretude, o que não é dividida do todo da realidade pelo conhecimento, pelo senso comum, pela linguagem. O que se pensa intuitivamente é o que se pensa na duração, e não com a inteligência que imobiliza o movimento e que procura reconstrui-lo com imobilidades justapostas. Pelo contrário, a "intuição parte do movimento, coloca, ou melhor, percebe-o como a realidade mesma, e não vê na imobilidade mais do que um movimento abstrato, um instantâneo tomado por nosso espírito na mobilidade" (p. 171).

Nossos hábitos, maneiras de falar, pensar e perceber o mundo estão soldados a essa imutabilidade e imobilidade das coisas, as quais Bergson afirma serem o próprio prolongamento da natureza. Nossa língua está atrelada a essa essência da inteligência cuja função é julgar e operar sob a construção de um predicado a um sujeito:

O sujeito, uma vez apenas nomeado, é definido como invariável; a variação consistirá na diversidade de estados que afirmaremos dele, passo a passo. Procedendo assim pela aposição de um predicado a um sujeito, o estável ao estável, seguimos a inclinação de nossa inteligência, conformamo-nos às exigências de nossa língua, e, para dizer tudo, obedecemos à natureza. (BERGSON, 2005, p. 205)

Ele critica este permanente enunciado de sujeito que predetermina o homem para a vida social e para o trabalho, legitimando um tipo de comunicação que se destina a isso. Além da linguagem, nossa percepção procede desta forma, recortando, "na continuidade de extensão, corpos escolhidos precisamente de tal maneira que possam ser tratados como invariáveis durante o tempo em que o considerarmos" (p. 206). A variação, se surgir, dar-se-á para nós como um estado que cedeu lugar a outro e que, por sua vez, não variará. Nesse sentido, linguagem, pensamento e percepção nos põem em presença de objetos, de pessoas, de nós mesmos como substâncias invariáveis. Objetivamos a vida, transformando-a em algo imutável e imóvel, justapomos estados e negamos a realidade mesma, sua duração. No entanto, a vida é indivisível enquanto duração pura.

A vida, assim, torna-se uma melodia: essa "continuidade indivisível e indestrutível de uma melodia em que o passado entra no presente e forma com ele um todo indiviso, que permanece indiviso e mesmo indivisível apesar do que aí se acrescenta a cada instante, ou melhor, graças ao que se acrescenta" ( $p$. 207). O pensamento intuitivo, ligado a uma duração que é crescimento, percebe a emergência de uma novidade imprevisível e ininterrupta. Um processo que é custoso e que por si só exige esforço, para fugirmos do pensamento habitual, banal e representativo; penoso, para desenraizarmos essa inclinação profunda em nos percebermos como substâncias invariáveis. O que sobra à metafísica e 


\section{Alice Copetti Dalmaso - Deisi Sangoi}

ao espírito - à intuição, portanto - parece ser resultado de um trabalho interior árduo e custoso. ${ }^{2}$ Parece-nos, assim, que a mudança não gera pânico, não estranha, já que é essencial à intuição, sendo ela mesma sentida apenas como pequenos instantes que se mostrariam como constante produção de novidade, criação, subjetividade.

Nesse sentido, podemos acompanhar Kastrup quando procura no conceito de duração de Bergson o próprio fundamento da invenção. Dos atos não-recognitivos que possibilitam movimentos inventivos, de uma maneira de ser no tempo que não nega, bloqueia ou impede a reinvenção de si e do mundo; de uma consciência que ultrapassa a separação rígida de nosso corpo com o dos outros, porque "é no espaço que as divisões são bem marcadas" (BERGSON, 2005, p. 169). A partir disso, direcionamos nossa atenção aos nossos meios formativos e de trabalho, criando um olhar especial à formação de professores, transmutando sua figura de tempo e lugar especial determinado como "formativo", traçando - de forma já naturalizada - uma identidade de professor. Nessa atmosfera inventiva - e permitindo-se pensar uma formação enquanto duração, transição -, abre-se o caráter de imprevisibilidade, de tempo que se torna ele mesmo invenção. E isso inclui, como premissa, um certo abandono de uma postura institucional que designa a representação de lugar do saber e da verdade.

De maneira geral, criamos e reproduzimos um espaço em que nossa ação é direcionada por uma inteligência que dificulta a percepção da consciência sobre o movimento da duração:

Toda ação visa obter um objeto do qual nos sentimos
privados ou então criar algo que ainda não existe. Nes-
se sentido muito particular, preenche um vazio e vai do
vazio para o pleno, de uma ausência para uma presen-
ça, do irreal para o real. Aliás, a irrealidade da qual se
trata aqui é puramente relativa à direção na qual se
engajou nossa atenção, pois estamos imersos em rea-
lidades e delas não podemos sair; só que, quando a
realidade presente não é aquela que procurávamos, fa-
lamos da ausência da segunda ali onde constatamos a
presença da primeira. Exprimimos assim o que temos
em função do que gostaríamos de obter. (BERGSON,
2005, p. 296-297)

Nosso modo de operar se encontra nessa dualização da vida. Da mesma forma que vamos do imóvel ao movente, ou seja, por estatizações do movimento, nos servimos do vazio para pensar o pleno. Agimos assim diante das circunstâncias da vida em quase todos os seus âmbitos (financeiro, cultural, político, estético, produtivo). Igualmente, torna-se comum nossa prática docente lidar com o real e com o cotidiano pela lógica da ausência, do que nos falta para uma "educação melhor": operamos cotidianamente com um ideal, 
Produções do invisível: considerações sobre o tempo

com a representação idealizada - de educação, de professor, de aluno - e com um vazio professoral que, aparentemente, precisa ser buscado e preenchido:

A concepção de vazio nasce aqui quando a consciência, em atraso com relação a si mesma, permanece presa à lembrança de um estado antigo, muito embora um outro estado esteja presente. Não é mais que uma comparação entre aquilo que é e aquilo que poderia ou deveria ser, entre pleno e pleno. (BERGSON, 2005, p. 306)

Conforme o autor, a não representação do mundo dessa forma demanda um esforço muito grande. Reside aí uma dificuldade em apreendermos a concretude do presente, do que se apresenta, da realidade ela mesma, saindo da lógica da construção de um perfil de professor. Instala-se um sentimento de impotência justamente pela negação do presente e do que nos chega de diferencial e problemático; negação do que está dado, do que está posto como vivível, e que este dado deva ser substituído:

O substituído só existe como concepção do espírito. Para continuar a vê-lo e, por conseguinte, para falar dele, é preciso virar as costas para a realidade, que corre do passado para o presente, de trás para frente. É o que fazemos quando negamos. Constatamos a mudança, ou, mais geralmente, a substituição, como veria o trajeto do carro um viajante que olhasse pra trás e só quisesse conhecer, em cada instante, o ponto no qual deixou de estar; ele sempre determinaria sua posição atual exclusivamente por referência àquela que acaba de deixar, em vez de exprimi-la em função de si mesma. (BERGSON, 2005, p. 318)

Nossos hábitos de ação que acabam impregnando e sustentando os hábitos de representação ${ }^{3}$ contribuem para criar uma atmosfera um tanto fatalista nos discursos recorrentes à educação, junto àqueles referentes a uma má qualidade do ensino, falta de estrutura familiar, indisciplina dos alunos, entre outros. Não é incomum percebermos a ânsia em alcançar um agir professoral que dê conta de um perfil de alunos imóveis, silenciosos - ou seja, inexistentes - ratificando uma representação de professor que mantém a ordem, e que acaba compondo um espaço vazio e, por vezes, repressor.

\section{Duração, processualidade: individuação e diferença}

Quando nos referimos à formação, nos inserimos na composição desse meio. E escrever sobre o tempo que dura implica também o desejo de nos desconstruirmos da imobilidade na qual a inteligência opera em demasia. $\mathrm{Na}$ processualidade que se trata em explicar, nos movimentos inventivos que funcionam com ela, o tempo é considerado como expressão da dimensionalidade do ser que se individua. Ou seja, durar refere-se a uma imediatidade do ser, do 


\section{Alice Copetti Dalmaso - Deisi Sangoi}

tempo de ser, que é modulável, mutante, sempre em devir, sempre em criação. Nesse sentido, trazemos a contribuição de Gilbert Simondon, para ajudar na significação de uma desconstrução de nós mesmos. Numa primeira análise, a busca por tentar encontrar um princípio de tudo que explique o indivíduo é criticada por Simondon. Habitualmente, invertemos a flecha do tempo (porque parecemos sempre procurar no passado algo que explique a realidade atual), buscando encontrar o elemento primordial que deu origem a um indivíduo pronto, realizado, acabado. $O$ interesse de Simondon é justamente abandonar a polaridade do indivíduo: o ponto de partida e ponto de chegada. Sua intenção é pensar na operação de individuação, no individuar-se, nesse intervalo ignorado em que reside a própria vida. Pensar o indivíduo como "palco ou teatro de individuação" (DA COSTA, 2002, p. 300), realizando-se na sua processualidade, sem procurar no passado um princípio que o justifique no hoje, posto que é no presente que o indivíduo se individua. Interessa-nos, assim como a Simondon, conhecer o indivíduo pela individuação e não a individuação pelo indivíduo.

Constrói-se um olhar atento a isso, a esse ente que se apresenta em sua imediatidade - e não à sua constituição material ou formal -, em sua própria operação de individuação, a essa zona, esse entre, para incitar o movimento de deixar de pensar o indivíduo pronto e acabado. Para tanto, pensemos que o indivíduo seja tomado como próprio "meio de individuação, um meio que implica uma realidade pré-individual, um campo de singularidades pré-individuais" (ORLANDI, 1993, p. 90). O que isso quer dizer? Que nossa natureza carrega uma carga em constante movimento de diferenciação, uma condição prévia de todo processo individuante. A individuação leva a diferença que portamos a aparecer e mesmo continuar aparecendo, diferenciando, sendo outros. Para a diferença mesma se fazer presente e, portanto, nos tornarmos de fato singulares, ela não pode senão diferenciar-se. Nesse sentido, o indivíduo "não só é resultado, mas é ele mesmo meio de individuação" (DELEUZE, 1993, p. 120): nos alimentamos desse meio, carregamos ele conosco, nosso suporte de realidade ainda não individualizado (e diferenciante).

Operando nessa reversão da lógica do princípio de individuação, observamos a eventualidade do ser: somos uma resolução parcial e relativa de nós mesmos portando o devir, este como sendo uma dimensão do ser: devir como uma capacidade que o ser tem de defasar-se a si próprio, "de resolver-se defasando-se" (SIMONDON, 1993, p. 101). Resolver-se, indo de um a outro, cancelando-se e fazendo surgir outros. O devir é a própria individuação, a própria operação enquanto se efetua fazendo com que a individuação seja uma aparição de fases no ser, como própria operação de devir enquanto se efetua. Eis aqui a processualidade que retorna; a duração em si. A duração, que é devir, é a própria operação de individuação; ambos os conceitos podem aqui funcionar como essa construção do eu: a invenção de si. Assim, percebermo-nos como esse algo ilimitado, carregado de problemas irresolutos, de uma potência de diferenciação infinita, mesmo que imperceptível. 
Vejamo-nos, então, como professores, em seu espaço formativo, tocado por esse olhar de um ser em constante processo, um olhar que age sobre ele, que funciona nele: pode, também ele, agir com seus alunos, sob o mesmo olhar (destituindo-se de um ideal, em que ele, escola e alunos devem progredir para uma formação rígida unificada, despotencializando o que cada um possui de singular e diferenciante)? A invenção só é possível quando nos destituímos de uma perspectiva recognitiva: idealização de um bom professor, do sujeito aluno ideal, colocado no lugar de objeto o qual lidamos e agimos sobre.

O olhar sobre nós mesmos, na maioria das vezes, persiste na construção de uma identidade de professor (representação de professor) e da negação da diversidade, da proliferação de singularidades, tanto no meio acadêmico quanto no escolar. Assim, preferimos pensar uma formação humana que se vê como "abandono da referência identitária e sua substituição pela processualidade" (ROLNIK, 1996, p. 4). Através dela, é possível que o vazio de sentido que existe - e que não é negado - abra-se à própria experiência do não-sentido e da emergência de novos modos de subjetivação. Uma formação pela continuidade, pela processualidade do que surge o tempo todo, e que é do caráter da imprevisibilidade da vida, do não-domínio de tudo. Isto é, assumindo os riscos inerentes à vida.

Não se trata de criarmos um outro espaço formativo e de utilizarmos um método para tal. Menos ainda de crítica à estrutura e currículo de um curso de formação de professores. Existe sim um desejo de uma formação que seja ela mesma criação, que põe o pensamento a funcionar. Construir uma cognição que não somente parta da prática reflexiva sobre um mundo diante de nós, mas que considere a produção de conhecimento, que é ativação, invenção de um mundo, construção de um (outro) corpo (DA COSTA, 2002). Como Kastrup, acreditamos numa política de invenção, ou seja, de um modo de operar. Modo de estar no mundo que implique abertura, desconstrução de figuras do saber e poder (representação de professor), e de uma vontade de aprendizagem de novos modos de ser e estar no mundo:

Por isso insisto que a discussão sobre formação do
professor não pode abrir mão da questão da política
cognitiva que praticamos. Política que implica a ultra-
passagem de nossa atitude recognitiva e que exige uma
luta permanente contra o cognitivista que insiste em se
instalar em nós. No campo da invenção, nada está ga-
rantido. Nada é desde sempre nem pra sempre. Tam-
bém não há um método único nem receitas infalíveis [...]
Pois ensinar é, em grande parte, compartilhar experiên-
cias de problematização. Estas podem ser fugazes,
emergindo no campo da percepção e se dissipando em
seguida. Mas é imprescindível a manutenção de sua
potência para a invenção de novas subjetividades e de
novos mundos. Por isso considero que no domínio da
formação, é preciso encontrar estratégias de constante 


\begin{abstract}
desmanchamento da tendência em ocupar o lugar do professor que transmite um saber. Penso que não se trata de determinismo nem de livre arbítrio; nem de submissão a um modelo existente, nem de boa vontade. $O$ caminho é de um aprendizado permanente. Trata-se de um processo lento, marcado por idas e vindas, mas só ele possibilita a criação de uma política cognitiva da invenção. (KASTRUP, 2005, p. 1287)
\end{abstract}

Uma política implica uma série de mudanças de paradigmas. Nesses escritos, atentamos basicamente em contribuir para uma mudança de percepção, ressoando na possibilidade de outros encontros nos espaços formativos, este funcionando como meio de individuação, operando, na duração, como potência individuante, meio individuante. É no contato com esse outro tempo, num tempo que é contato consigo mesmo e com o mundo, que um campo de possibilidades se efetua: repensar uma formação de professores idealizada, rígida e fixa. Esse tempo cronológico e fragmentado, instituído nos locais de ensino, não nos interessa. Interessa-nos o que pode ser feito nele e com ele: transformálo num tempo em que se pode olhar para cada um de nós como outros, percebendo-nos outros, em mutação e em movimento, e que assim, possamos operar sob outro tempo. Tempo que é ele mesmo produção de subjetividades, singularidades e diferenças.

Não facilmente, isso implica um aprender a viver os acontecimentos que provocam rupturas, desequilíbrios e desassossego. Acolhimento dos múltiplos que vivem em nós pela própria multiplicação das diferenças inerentes à individuação. Individuação que abarca a coletividade e que "viveria no atual e, caso fosse capaz de julgar, sempre afirmaria apenas a existência do presente" (BERGSON, 2005, p. 318). Trata-se, acima de tudo, de desenvolver um olhar do invisível à vida que não cessa de vibrar.

\title{
Referências
}

BERGSON, H. (1903). Introdução à metafísica. Traduzido por Franklin Leopoldo e Silva. São Paulo: Nova Cultural, 2005, p. 19-60.

. (1934). O pensamento e o movente (Introdução). Traduzido por Franklin Leopoldo e Silva. São Paulo: Nova Cultural, 2005, p.149-224. . (1859-1941). A evolução criadora. Traduzido por Bento Prado Neto. São Paulo: Martins Fontes, 2005, p. 295-391.

DA COSTA, R. Gilbert Simondon e a operação de individuação. In: LEÃO, L. (Org.). Interlab: labirinto do pensamento contemporâneo. São Paulo: lluminuras, 2002. 362p.

DELEUZE, G. Gilbert Simondon, o indivíduo e sua gênese físico-biológica. In: 0 reencantamento do concreto. Cadernos de subjetividade/Núcleo de Estudos 
e Pesquisas da Subjetividade do Programa de Pós-Graduados em Psicologia Clínica da PUC-SP, v. 1, n. 1, São Paulo, 1993.

DELEUZE, G.; PARNET, C. Diálogos. São Paulo: Escuta, 1998. 184p.

KASTRUP, V. Políticas cognitivas na formação do professor e o problema do devir-mestre. Educação Social, v. 26, n. 93, p. 1273-1288, 2005. Disponível em: <http://www.cedes.unicamp.br>.

A invenção de si e do mundo: uma introdução do tempo e do coletivo no estudo da cognição. Belo Horizonte: Autêntica, 2007. 256 p.

ORLANDI, L. B. L. O indivíduo e sua implexa pré-individualidade. In: 0 reencantamento do concreto. Cadernos de subjetividade/ Núcleo de Estudos e Pesquisas da Subjetividade do Programa de Pós-Graduados em Psicologia Clínica da PUC-SP, v. 1, n. 1, São Paulo, 1993.

ROLNIK, S. Toxicômanos de identidade: subjetividade em tempo de globalização. Reelaboração de artigo publicado no caderno "Mais!" da Folha de São Paulo, 19/05/96. Disponível em: <http://caosmose.net/suelyrolnik/pdf/ viciados_em_identidade.pdf >. Acesso em: 30 set. 2011

SIMONDON, G. A gênese do indivíduo. In: O reencantamento do concreto. Cadernos de subjetividade/ Núcleo de Estudos e Pesquisas da Subjetividade do Programa de Pós-Graduados em Psicologia Clínica da PUC-SP, v. 1, n. 1, São Paulo, 1993.

\section{Notas}

1 "Com efeito, o que é a inteligência? A maneira humana de pensar. Ela nos foi dada, como o instinto à abelha, para dirigir nossa conduta. Uma vez que a natureza nos destinou a utilizar e a dominar a matéria, a inteligência só evolui com facilidade no espaço e só se sente à vontade no domínio do inorganizado. Originalmente, ela se destina à fabricação; manifesta-se por uma atividade que prefigura a arte mecânica e por uma linguagem que anuncia a ciência - tudo mais na mentalidade primitiva é crença e tradição. $O$ desenvolvimento normal da inteligência efetuase, pois, na direção da ciência e da técnica. Uma mecânica ainda grosseira suscita uma matemática ainda imprecisa: esta, tornando-se científica e fazendo surgir em torno dela outras ciências, aperfeiçoa indefinidamente a arte mecânica. Ciência e arte nos introduzem assim na intimidade de uma matéria que uma pensa e outra manipula. Por este lado a inteligência terminaria, em princípio, por atingir um absoluto." (BERGSON, 2005, p. 214).

\footnotetext{
2 "Repudiamos, pois, a facilidade. Recomendamos uma certa maneira difícil de pensar. Prezamos acima de tudo o esforço. Como alguns puderam se enganar? Não diremos nada dos que queriam que nossa 'intuição' fosse instinto ou sentimento. Nenhuma linha do que escrevemos se presta a tal interpretação. E em tudo o que escrevemos há a afirmação contrária: nossa intuição é reflexão. Mas porque chamamos a atenção para a mobilidade que está no fundo das coisas, pretendeu-se que encorajávamos não sei que relaxamento do espírito." (BERGSON, 2005, p. 222)

3 "Não deve causar espécie, portanto, que os hábitos da ação impregnem os da representação e que nosso espírito perceba sempre as coisas na exata ordem em que temos o costume de nos figurá-las quando nos propomos a agir sobre elas." (BERGSON, 2005, p. 321).
} 


\section{Alice Copetti Dalmaso - Deisi Sangoi}

\section{Correspondência}

Deisi Sangoi -Av. Roraima, Prédio 16, sala 3334 A - Campus Universitário, Camobi, CEP: 97105900 - Santa Maria, RS - Brasil.

E-mail: alicedalmaso@gmail.com - deisisf@gmail.com

Recebido em 21 de dezembro de 2011

Aprovado em 07 de junho de 2012 